\title{
Effects of Concentrated Ambient Particles on Airway Responsiveness and Pulmonary Inflammation in Pulmonary Hypertensive Rats
}

\author{
Yu-Chen Lei, Ming-Chih Chen, Chang-Chuan Chan \\ Institute of Occupational Medicine and Industrial Hygiene, College of Public Health, National Taiwan \\ University, Taipei, Taiwan
}

\author{
Peng-Yau Wang, Chung-Te Lee \\ Institute of Environmental Engineering, College of Engineering, National Central University, \\ Chung Li, Taiwan
}

\section{Tsun-Jen Cheng}

Institute of Occupational Medicine and Industrial Hygiene, College of Public Health, National Taiwan

University, Taipei, Taiwan

\begin{abstract}
Epidemiological studies have associated particulate air pollution with exacerbation of lung function in human populations. However, the relationship between ambient particles and lung function in animal studies has been inconsistent. In order to investigate the effects of concentrated ambient particles (CAPs) on airway responsiveness, we exposed pulmonary hypertensive rats to CAPs using particle concentrator at an EPA of Taiwan supersite, located at a traffic busy urban area nearing Taipei city. The exposure group $(n=5)$ was exposed to CAPs for $6 \mathrm{~h}$ each day for 3 consecutive days (mean mass concentration $=371.7 \mu \mathrm{g} / \mathrm{m}^{3}$ ), while a control group $(n=6)$ was exposed to HEPA-filtered air. Whole-body barometric plethysmography was used to measure respiratory frequency, tidal volume, and airway responsiveness before and after exposure. Enhanced pause (Penh) was used as an indicator of airway responsiveness. To improve the accuracy of airway responsiveness measurement, we controlled temperature and humidity. Further, airway responsiveness was determined $5 \mathrm{~h}$ after particle exposure to overcome the stress effect in nose-only exposure chambers. After CAPs exposure, we found decreased respiratory frequency and increased tidal volume $(p<.05)$. Using the methacholine challenge test, a significant difference of Penh measured before and after experiment was observed in the CAPs group $(p<.05)$, but not in the filtered air group. Further analysis showed that the Penh difference before and after exposure in the CAPs group was significantly greater than that in the filtered air group $(p<.05)$. We conclude that CAPs could induce airway hyperresponsiveness in pulmonary hypertensive rats.
\end{abstract}

Epidemiological studies have observed an association between particulate air pollution and respiratory morbidity and mortality (Dockery \& Pope, 1994; Schwartz et al., 1994; Pope

Received 4 January 2004; accepted 5 May 2004.

This study was funded by EPA of Taiwan (EPA-92-FA11-03-A134) and NSC92-2621-Z-002-014. We also thank the Environmental Analysis Laboratory of EPA, Taiwan, for technical assistance.

Address correspondence to Dr. Tsun-Jen Cheng, Institute of Occupational Medicine and Industrial Hygiene, College of Public Health, National Taiwan University, No. 1 Ren-Ai Rd., Sec. 1, Taipei, Taiwan, 10018. E-mail: tcheng@ha.mc.ntu.edu.tw et al., 1999, 2002). Particulate air pollution is also associated with increased emergency-department visits for asthma and chronic obstructive pulmonary diseases (Schwartz, 1993; Schwartz et al., 1993). In panel-based lung-function studies, declines in forced expired volume (FEV), force vital capacity (FVC), and peak expiratory flow (PEF) were also reported to be associated with increased particulate air pollution (Ackermann-Liebrich et al., 1997; Pekkanen et al., 1997; Peters et al., 1997; Peacock et al., 2003). However, laboratory observations on human volunteers exposed to concentrated ambient particles (CAPs) or diesel exhaust particles were not consistent (Salvi et al., 1999; Gong et al., 2003). 
Animals have also been used to test if particulate material (PM) can alter lung function. The effects of CAPs on pulmonary function alteration were less consistent in animal studies (Clarke et al., 1999; Godleski et al., 2000; Gordon et al., 1998). One study reported altered peak expiratory flow (PEF) and tidal volume (TV) in chronic bronchitis rats with exposure to CAPs (Clarke et al., 1999), while the other study didn't observe significant change in pulmonary function in monocrotaline-induced pulmonary hypertension rats (Gordon et al., 1998).

Recently, a noninvasive whole-body plethysmography system (Buxco, Troy, NY) has been developed to measure airway responsiveness. Enhanced pause (Penh) as an indicator of airway responsiveness has been proved to be highly correlated with lung resistance, which is measured with traditional methods (Hamelmann et al., 1997). Several studies have used this methodology but showed inconsistent results. One study observed an airway hyperresponsiveness (AHR) in asthmatic mice with residual oil fly ash (ROFA) inhalation, but not with CAPs (Goldsmith et al., 1999). The other study found that ROFA alone did not induce AHR in asthmatic mice (Hamada et al., 2000). A recent study observed a mild increase in airway resistance in asthmatic mice after combined exposure to CAPs and ozone (Goldsmith et al., 2002).

Inconsistency of these studies may originate from animal susceptibility, experimental design, airway responsiveness measurement, and particle concentration and components. It is likely that restriction in a confined nose-only exposure chamber for hours may induce the release of epinephrine and increase the sympathetic tone, resulting in dilation of the airway. The temperature and humidity during nose-only exposure may also affect the measurement of airway resistance using whole-body plethysmography (Lundblad et al., 2002). Therefore, we measured airway responsiveness under a controlled environment and with a time lag when noninvasive barometric plethysmography was used in this study.

\section{MATERIALS AND METHODS}

\section{Animals}

Male Sprague-Dawley rats (average body weight $318.7 \pm$ $8.3 \mathrm{~g}$ ) were obtained from the National Laboratory Animal Breeding and Research Center, Taiwan. They were housed in plastic cages on Aspen chip bedding and were provided with lab diet 5001 and water ad libitum, except during the exposure. Animals were maintained on a 12-h light/dark cycle at $22 \pm 1{ }^{\circ} \mathrm{C}$ and $55 \pm 10 \%$ relative humidity. A single intraperitoneal injection of monocrotaline (MCT, Sigma Chemical Co., $60 \mathrm{mg} / \mathrm{kg}$ ) was administered to each rat (Kodavanti et al., 1998). Fourteen days after MCT treatment, CAPs exposure was conducted. All protocol used in this experiment was approved by National Taiwan University's animal care and use committee.

\section{Experimental Design}

In our previous work, the airway resistance (Penh) measured immediately after nose-only CAP exposure was significantly lower than that before the exposure. This was likely resulted from the dilatation of airway, which was induced by the sympathetic stress due to the nose-only chamber effect. Thus, we conducted a study to determine how long it took for the airway dilatation to return to the baseline after animals were removed from the nose-only chamber. We found that the Penh didn't return to the baseline for at least $5 \mathrm{~h}$ after leaving the nose-only chamber (Figure 1). Thus, modifications have been made to adjust for the chamber effect in the subsequent experiment. Animals were placed in the nose-only tubes before the PM or filtered air exposure; then airway responsiveness, respiratory frequency, and tidal volume were measured $5 \mathrm{~h}$ after leaving the tube. After PM or filtered air exposure, airway responsiveness, respiratory frequency, and tidal volume were again measured $5 \mathrm{~h}$ after leaving the tube. Additionally, plethysmography operation was conducted under controlled temperature $\left(20 \pm 2^{\circ} \mathrm{C}\right)$ and humidity $(50 \pm 5 \%)$ to improve the accuracy of airway responsiveness measurement.

The experimental setup is given in Figure 2. Animals were treated with MCT for 14 days then divided into CAPs and filter air groups. At day 14, animals were first restricted in a nose-only chamber from 7 a.m. to 1 p.m., for $6 \mathrm{~h}$, in room air at our laboratory. Then, after $5 \mathrm{~h}$ of rest, preexposure pulmonary function and airway responsiveness of individual animals were determined. At days 15, 16, and 17, animals were exposed to CAPs or filter air from 7 a.m. to 1 p.m., for 6 h. At day 17, postexposure respiratory frequency, tidal volume, and airway responsiveness were also conducted $5 \mathrm{~h}$ after release from nose-only exposure chamber. Penh was measured without challenge (named as baseline data) and with challenge using normal saline and methacholine. Animals were sacrifice at day 19 to collect bronchoalveolar lavage (BAL), peripheral blood, and lung tissue.

\section{Exposure Facilities and Characterization of Ambient and Concentrated Particle Exposure}

The methodology for exposing pulmonary hypertensive rats with concentrated PM has been described in our previous study (Cheng et al., 2003; Lei et al., 2004). In brief, the exposure laboratory was located in Hsin-Chuan, a Taiwan EPA supersite. Ambient particles from Hsin-Chuan were concentrated using a modified ultrafine particle concentrator (Sioutas et al., 1999). The particle concentrator used virtual impactor technology in which $110 \mathrm{~L} / \mathrm{min}$ flow was channeled through a saturator, cooler, impactor, and diffusion dryer to generate concentrated particles with aerodynamic diameters between 0.01 and $2.5 \mu \mathrm{m}$. The concentrator output was about $10 \mathrm{~L} / \mathrm{min}$ at a negative pressure of about $2 \mathrm{~mm} \mathrm{Hg}$. Air containing concentrated particles was directed into the nose-only exposure chambers. 


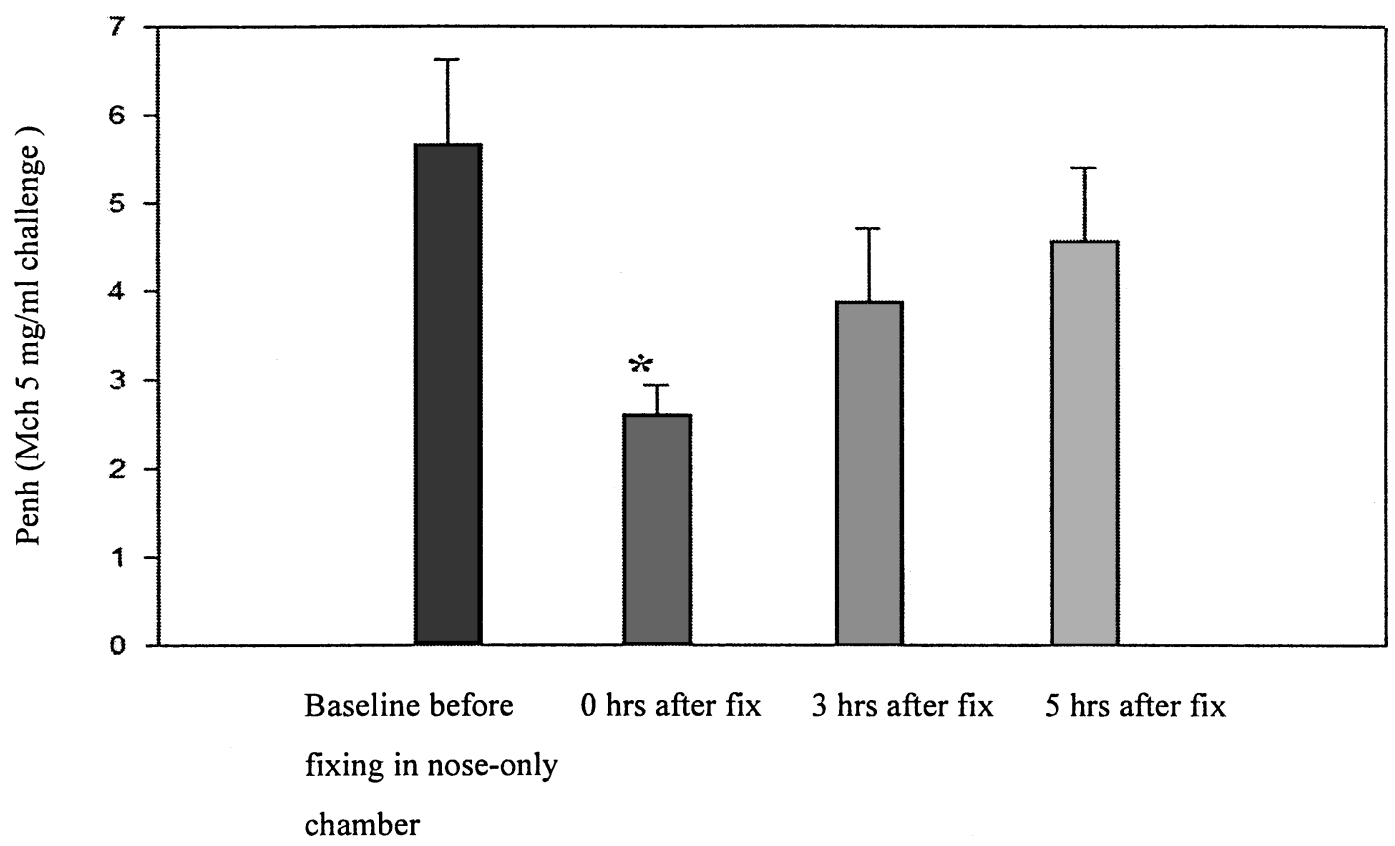

FIG. 1. Penh at 0,3 , and $5 \mathrm{~h}$ after being removed from the nose-only exposure chamber $(n=4)$. Bars present mean \pm standard error. Asterisk indicates significant at $p<.05$ compared to baseline before fixing in nose-only chamber.

Average CAPs mass concentration during exposure was calculated from the mass collected on filters and the elemental composition of the particles was determined using x-ray fluorescence (XRF). In addition, concentrations of water-soluble ions and carbonaceous content of $\mathrm{PM}_{2.5}$ were also monitored at the Taiwan EPA supersite. An ambient carbon particulate monitor (5400, Rupprecht \& Patashnick Co., Inc.) was used to determine the concentrations of organic and elemental carbons in $\mathrm{PM}_{2.5}$. An ambient particulate nitrate monitor (8400N, Rupprecht \& Patashnick Co., Inc.) and an ambient particulate sulfate monitor (8400S, Rupprecht \& Patashnick Co., Inc.) were used to determine the concentrations of nitrate and sulfate. These data were used to describe the characteristics of air pollutants during CAPs exposure (Table 1).

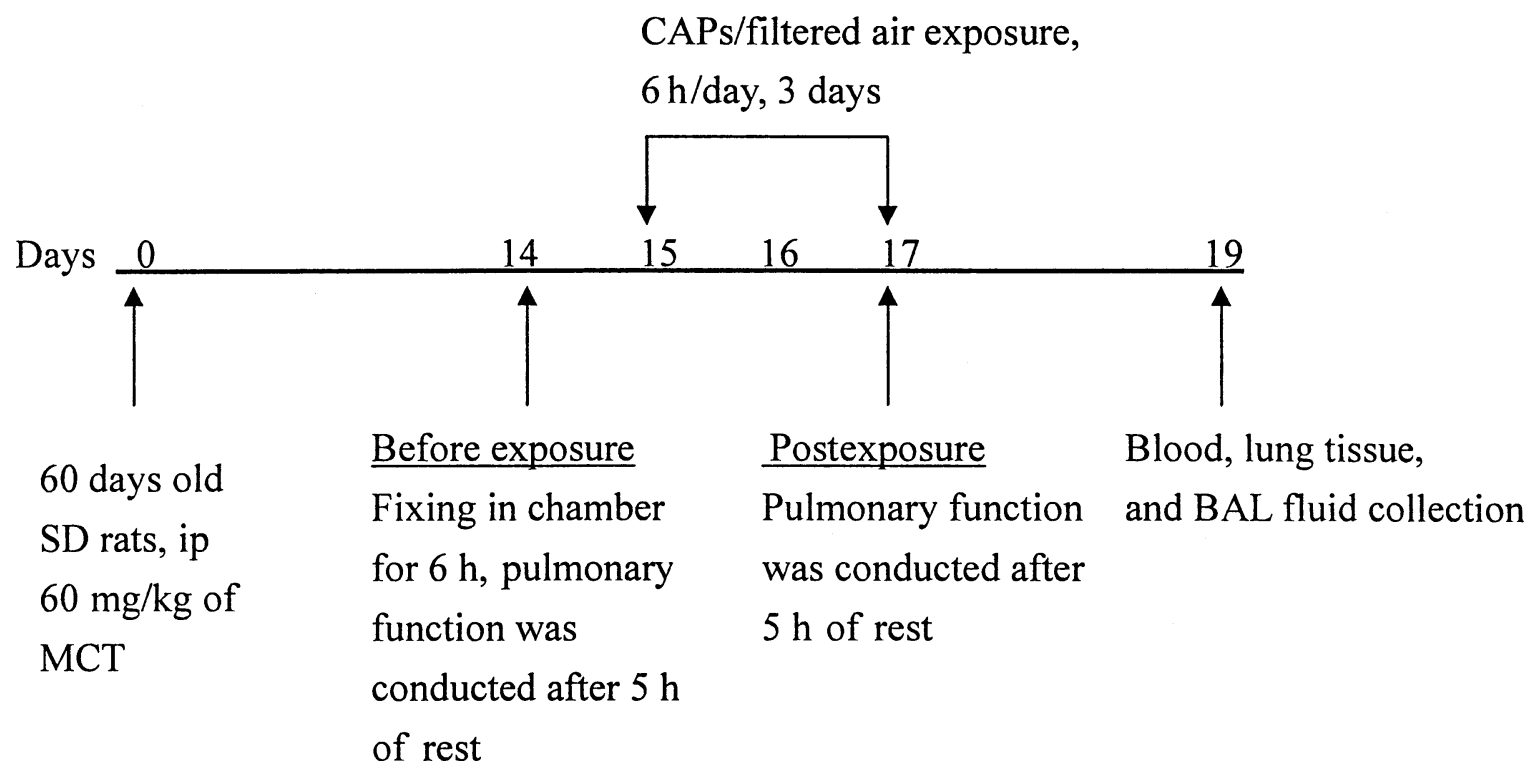

FIG. 2. Schematic summary of exposure protocol in the present study. 
TABLE 1

Characterization of concentrated $\mathrm{PM}_{2.5}$ and ambient $\mathrm{PM}_{2.5}$ during exposure

\begin{tabular}{|c|c|}
\hline Components & Concentration \\
\hline \multicolumn{2}{|l|}{$\begin{array}{l}\text { From Teflon filters collected } \\
\text { from concentrator }\end{array}$} \\
\hline $\begin{array}{l}\text { Concentration of } \mathrm{PM}_{2.5}\left(\mu \mathrm{g} / \mathrm{m}^{3}\right) \\
\text { during exposure }\end{array}$ & $371.3(208.3)^{d}$ \\
\hline \multicolumn{2}{|l|}{$\begin{array}{l}\text { Percentage of elemental } \\
\text { component }(\mathrm{XRF})\end{array}$} \\
\hline K & $33.7(17.0)$ \\
\hline S & $25.5(8.4)$ \\
\hline $\mathrm{Al}$ & $6.1(3.1)$ \\
\hline $\mathrm{Fe}$ & $4.7(2.5)$ \\
\hline $\mathrm{P}$ & $2.7(2.8)$ \\
\hline $\mathrm{Ca}$ & $2.3(1.3)$ \\
\hline $\mathrm{Si}$ & $2.1(1.5)$ \\
\hline $\mathrm{Zn}$ & $1.7(1.1)$ \\
\hline Mo & $0.5(0.3)$ \\
\hline $\mathrm{Ti}$ & $0.4(0.2)$ \\
\hline $\mathrm{Cu}$ & $0.3(0.3)$ \\
\hline $\mathrm{Mn}$ & $0.2(0.07)$ \\
\hline $\mathrm{Pt}$ & $0.07(0.07)$ \\
\hline V & $0.06(0.03)$ \\
\hline Co & $0.04(0.03)$ \\
\hline \multicolumn{2}{|l|}{$\begin{array}{c}\text { Ambient } \mathrm{PM}_{2.5} \text { from Taiwan EPA } \\
\text { supersite during experiment }\end{array}$} \\
\hline Concentration of $\mathrm{PM}_{2.5}\left(\mu \mathrm{g} / \mathrm{m}^{3}\right)$ & $26.6(22.9)$ \\
\hline Organic carbon on $\mathrm{PM}_{2.5}\left(\mu \mathrm{g} / \mathrm{m}^{3}\right)$ & $6.6(3.4)$ \\
\hline Elemental carbon on $\mathrm{PM}_{2.5}\left(\mu \mathrm{g} / \mathrm{m}^{3}\right)$ & $8.7(4.4)$ \\
\hline Sulfate on $\mathrm{PM}_{2.5}\left(\mu \mathrm{g} / \mathrm{m}^{3}\right)$ & $3.1(2.1)$ \\
\hline Nitrate on $\mathrm{PM}_{2.5}\left(\mu \mathrm{g} / \mathrm{m}^{3}\right)$ & $4.9(5.4)$ \\
\hline
\end{tabular}

${ }^{a}$ Mean (standard deviation).

\section{Measurement of Respiratory Frequency, Tidal Volume, and Airway Responsiveness}

Pulmonary functions including respiratory frequency, tidal volume, and airway responsiveness were measured using whole-body plethysmography (Buxco, Troy, NY). Approximately $5 \mathrm{~h}$ after exposure, rats were placed in a whole-body plethysmograph, and box pressure wave was recorded via a transducer and computer system. After establishing stable baseline data over a period of $10 \mathrm{~min}$, rats were first challenged with aerosolized normal saline $(0.9 \%)$ for $5 \mathrm{~min}$, and measurements were recorded for $5 \mathrm{~min}$. Then methacholine (MCh, $5 \mathrm{mg} / \mathrm{ml}$, Sigma) was challenged for $5 \mathrm{~min}$ and recorded for $5 \mathrm{~min}$. Each measurement would be recorded every $10 \mathrm{~s}$. Enhanced pause (Penh) as an indicator of airway responsiveness was calculated as suggested by Hamelmann et al. (1997). The concentration of methacholine used in this study was based on our previous work, which indicated that airway responsiveness of rat reached the peak at this concentration.

\section{Bronchoalveolar Lavage Analysis}

Animals were sacrificed $48 \mathrm{~h}$ after exposure. BAL fluid was collected by washing the airway with a phosphate-buffered saline solution (PBS, $\mathrm{pH} 7.4,28 \mathrm{ml} / \mathrm{kg}$ body weight) 5 times. Lavage fluid was used to determine the total number of cells and cell differential counts. Macrophage, lymphocyte, neutrophils, eosinophils, and basophils were counted under light microscopy (200 cells/slide). The remaining lavage fluid was used for the analysis of total protein and LDH activity. LDH activity was determined by autoanalyzer at National Taiwan University Hospital. Total protein was determined using a total protein assay kit (BioRad Co.). Cytokine interleukin-6 (IL-6) and tumor necrosis factor (TNF)- $\alpha$ were also determined using a specific enzyme-linked immunosorbent assay (ELISA) kit (R\&D System Co.).

\section{Statistical Analysis}

The SAS software package, version 8, was used for statistical analysis. Student's $t$-test was used to compare the effects on the CAPs-exposed group with the filtered air control group on various indices of inflammation markers in BAL and pulmonary function. The results of pulmonary function were compared in terms of the percent of difference between preexposure and postexposure:

$$
\begin{aligned}
& \begin{array}{l}
\text { Percent difference } \\
\text { postexposure measurement }- \text { preexposure measurement }
\end{array} \\
& \quad \times 100 \%
\end{aligned}
$$

The percent differences were also compared between the CAPs and filtered air control groups. Type I error rate was set at .05 for significance.

\section{RESULTS}

\section{Respiratory Frequency, Tidal Volume, and Airway Responsiveness}

Results for respiratory frequency and tidal volume are illustrated in Figure 3. Individual changes due to CAPs or filtered air exposure were demonstrated as the percent difference between preexposure and postexposure measurements. After experiment, both CAPs and filtered air exposure groups demonstrated decreased respiratory frequency and increased tidal volume, but only the CAPs exposure group measurements reached statistical significance $(p<.05)$.

Figure 4 illustrates airway responsiveness at baseline and with the challenge of normal saline and $\mathrm{MCh}$ after exposure to CAPs and filtered air. The values for pre- and postexposure for Penh at baseline and with the challenge of normal saline were not different in either the CAPs or filtered air groups. However, with Mch challenge, a significant increase of Penh was observed in animals exposed to CAPs $(p<.05)$. A similar increase was not observed in the filtered air group. Further analysis showed that the Penh difference for pre- and 


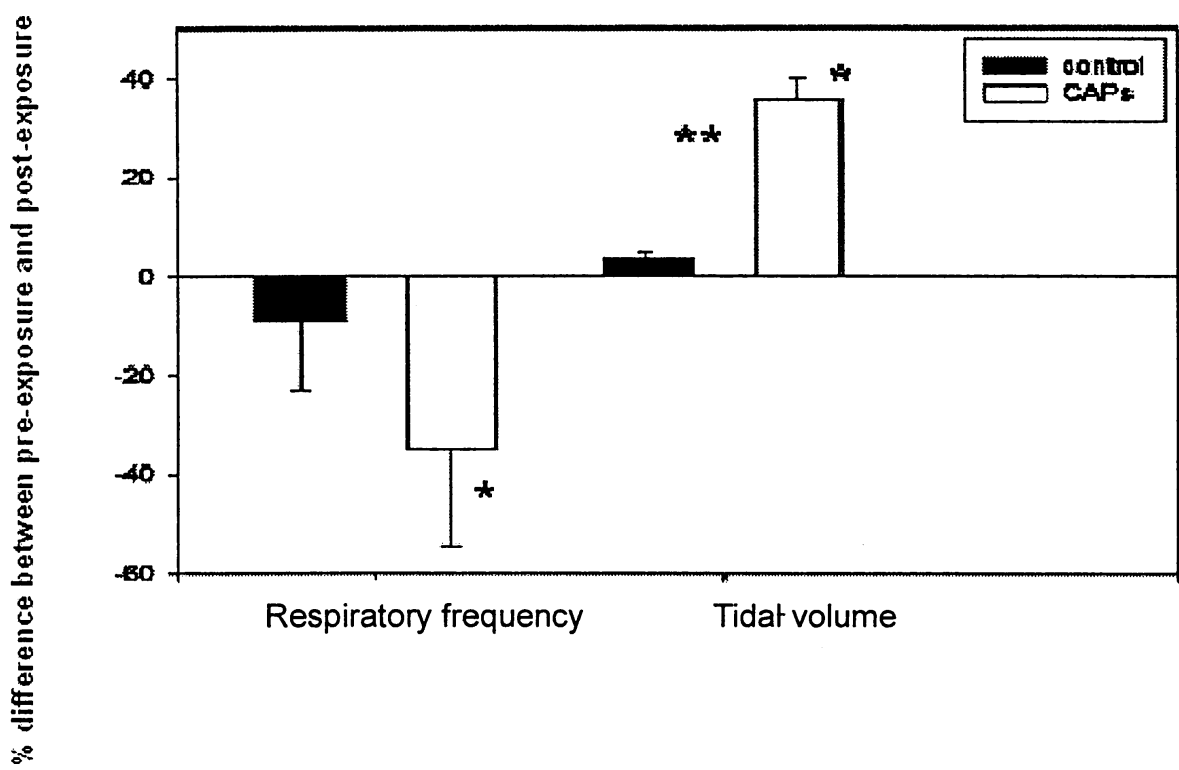

FIG. 3. Percentage of difference of respiratory frequency and tidal volume, pre- and postexposure to filtered air and CAPs. Bars present mean \pm standard error. Asterisk indicates significance at $p<.05$ for comparison between pre- and postexposure; double asterisk, significance at $p<.05$ for comparison between CAPs and filtered air group.

postexposure in the CAPs group was significant higher than that in the filtered air group $(p<.05)$.

\section{Bronchoalveolar Lavage Analysis}

Inhalation exposure to CAPs caused a significant increase in the total cells as compared to the filtered air group $(p<.05$,
Table 2). Similarly, a significantly elevated neutrophils percentage was observed in the CAPs-exposed group $(p<.05)$. However, there was no difference in the percentage of macrophages, lymphocytes, and eosinophils. In lung injury markers, total protein and lactate dehydrogenase (LDH) in BAL were significantly higher in the CAPs-exposed group ( $p<.05$, Table 3 ).

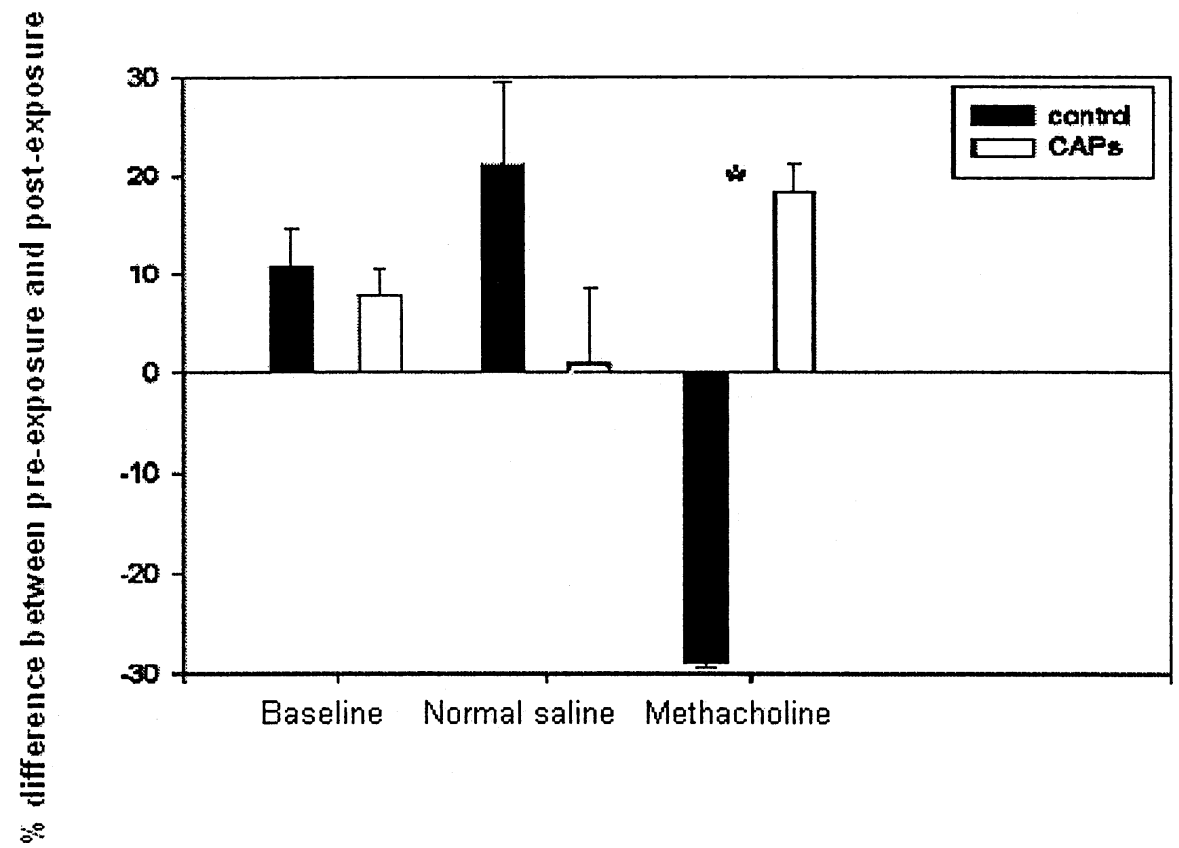

FIG. 4. Percentage of difference of airway responsiveness (Penh) in response to normal saline and MCh pre- and postexposure to filtered air and CAPs. Bars present mean \pm standard error. Asterisk indicates significance at $p<.05$ for comparison between CAPs and filtered air group. 
TABLE 2

Cell number and cell differential in BAL after filtered air and CAPs exposure

\begin{tabular}{lcc}
\hline & $\begin{array}{c}\text { Filtered air } \\
(n=6)\end{array}$ & $\begin{array}{c}\text { CAPs exposure } \\
(n=5)\end{array}$ \\
\hline Total cells $\left(\times 10^{4}\right.$ cell $)$ & $84.8 \pm 4.1$ & $187.9 \times 5.7^{a}$ \\
Marcrophages (\%) & $57.4 \pm 2.6$ & $51.2 \pm 2.7$ \\
Lymphocytes (\%) & $37.3 \pm 2.8$ & $30.8 \pm 1.4$ \\
Neutrophils (\%) & $3.6 \pm 1.7$ & $14.7 \pm 2.3^{a}$ \\
Eosinophils (\%) & $1.4 \pm 0.7$ & $1.7 \pm 0.9$ \\
Basophils (\%) & $0.4 \pm 0.7$ & $0.7 \pm 0.5$ \\
\hline
\end{tabular}

Note. Values are given as mean \pm standard error.

${ }^{a}$ Significant at $p<.05$.

The concentration of cytokine IL-6 protein in BAL fluid also increased after CAPs exposure $(p<.05)$. No difference was found in BAL TNF- $\alpha$ level between CAPs and filtered air exposure.

\section{DISCUSSION}

This goal of the present study was to investigate whether exposure to CAPs caused lung inflammation and altered respiratory frequency, tidal volume, and airway responsiveness in MCT-treated pulmonary hypertensive rats. We found exposure to CAPs caused significant lung inflammation and injury. We also observed that CAPs exposure caused alteration in respiratory frequency and tidal volume, and increased airway responsiveness with MCh challenge.

Although MCT-treated pulmonary hypertensive models have been used in a number of studies to investigate the effect of particles (Gordon et al., 1998; Cassee et al., 2002; Lei et al., 2004), they may not be perfect models for humans because monocrotaline induces an inflammation in the lower respiratory tract in rodents that is not observed in humans (Kodavanti et al., 1998). However, this model has been widely used and the results can be used to compare with other studies. Furthermore, the inflammation in the lower respiratory tract, which peaks at 14 days after MCT injection, makes these rats more sensitive to PM exposure.

TABLE 3

Lung injury and cytokine concentration in BAL after CAPs exposure

\begin{tabular}{lrc}
\hline & $\begin{array}{c}\text { Filtered air } \\
(n=6)\end{array}$ & $\begin{array}{c}\text { CAPs exposure } \\
(n=5)\end{array}$ \\
\hline Total protein $(\mathrm{mg} / \mathrm{ml})$ & $1.6 \pm 0.2$ & $2.6 \pm 0.3^{a}$ \\
LDH $(\mathrm{U} / \mathrm{L})$ & $11.2 \pm 4.7$ & $33.8 \pm 8.8^{a}$ \\
TNF- $\alpha(\mathrm{pg} / \mathrm{ml})$ & $20.2 \pm 2.8$ & $19.8 \pm 2.5$ \\
IL-6 $(\mathrm{pg} / \mathrm{ml})$ & $129.8+4.9$ & $141.4+7.4$ \\
\hline
\end{tabular}

Note. Values given as mean \pm standard error.

${ }^{a}$ Significant at $p<.05$.
Previous studies have shown an increased percentage of neutrophils and total cells in BAL in animals exposed to CAPs (Gordon et al., 1998; Clarke et al., 2000; Lei et al., 2004). In the same studies, indications of pulmonary injury including protein and LDH activity in BAL were also observed. Our study had similar findings.

This study also demonstrated that exposure to CAPs induced proinflammatory cytokine IL-6 protein in BAL in pulmonary hypertensive rats. In our previous study, BAL IL-6 also increased in rats exposed to CAPs during Asian dust events (Lei et al., 2004). The expression of IL-6 in BAL suggests that CAPs cause pulmonary inflammation in part through the release of proinflammatory cytokines (Monn \& Becker, 1999). We did not observe an increase in TNF- $\alpha$ level after CAPs exposure. It is not clear why TNF- $\alpha$ levels were not increased with CAP exposure. A recent in vitro study showed that particle-adsorbed endotoxin caused the activation of alveolar macrophages, while insoluble CAPs accounted for the enhanced cytokine release in primed alveolar macrophages incubated with CAPs (Imrich et al., 2000). However, specific elements in the insoluble part of PM were not associated with the production of TNF- $\alpha$ in the same study. Another study further indicated that the production of TNF- $\alpha$ in response to CAPs was correlated with endotoxin (Ning et al., 2000). The role of endotoxin in this study is not clear. The exact mechanisms through which CAPs induce TNF- $\alpha$ need more animal studies.

Particulate air pollution is associated with declines in forced expired volume (FEV), force vital capacity (FVC), and peak expiratory flow (PEF) in epidemiological studies (AckermannLiebrich et al., 1997; Pekkanen et al., 1997; Peters et al., 1997; Peacock et al., 2003); however, laboratory observations were less consistent (Salvi et al., 1999; Gong et al., 2003). In experimental human studies, no significant alterations in lung function have been observed in healthy volunteers or asthmatic patient exposed to concentrated ambient particles (Gong et al., 2003) and diesel engine exhaust (Salvi et al., 1999). The pulmonary function test (PFT) results from animal studies were also inconsistent (Clarke et al., 1999; Gordon et al., 1999). Recently, whole-body plethysmography has been developed to assess pulmonary function and found the calculated indicator of enhanced pause (Penh) to be highly correlated with lung resistance as measured by traditional methodology (Hamelmann et al., 1997). A major advantage of unrestrained plethysmography is the ability to monitor airway hyperresponsiveness without anesthetic and invasive treatment. However, studies using this new methodology in investigating the PM effects have been inconsistent (Goldsmith et al., 1999, 2002; Hamada et al., 2000).

A recent study pointed out that Penh measurement may be affected by the humidity and temperature of ambient conditions (Lundblad et al., 2002). In our experiment, plethysmography was conducted in a controlled-temperature and -humidity environment to improve the accuracy of the air responsiveness measurement. Furthermore, we modified the experimental protocol to adjust the nose-only chamber effect, which can increase 
sympathetic tone, resulting in epinephrine excretion and dilation of the airway. With environmental control and measurement about $5 \mathrm{~h}$ after the exposure, our results revealed acute effects of CAPs, including decreased respiratory frequency, increased tidal volume, and increased airway responsiveness with the challenge of MCh in pulmonary hypertensive rats. Although ROFA has been reported to induce airway hyperresponsiveness, CAPs alone did not cause this kind of change (Goldsmith et al., 1999, 2002). To the best of our knowledge, this is the first study demonstrating that CAPs could induce airway hyperresponsiveness in rats.

In the present study, pulmonary inflammation was observed $48 \mathrm{~h}$ after exposure. Thus, it was not clear whether pulmonary inflammation affected the increased airway responsiveness. However, our previous data indicated that significant alterations in airway responsiveness were observed only for few hours after CAPs exposure (unpublished data). It is likely that the increased airway responsiveness induced by CAPs in this study resulted from the direct stimulus on the airway nerve endings instead of from pulmonary inflammation. Irritant compounds on urban PM, including sulfate and aldehyde, may account for the changes in airway responsiveness (Leikauf, 2002; Tunnicliffe et al., 2003). Our data collected from the XRF analysis and the supersite suggest these particles were from motor vehicle exhaust. However, we are not clear which component accounts for the alteration in airway responsiveness based on our current design. Although there was one study conducted at Boston suggesting that $\mathrm{Al}$ and $\mathrm{Si}$ are associated with altered lung function (Goldsmith et al., 2002), the data on the components responsible for the alteration of airway responsiveness are limited. Thus, to determine the compounds accountable for increased airway responsiveness, we need to conduct more studies using PM with a variety of components.

With careful study design, we observed airway hyperresponsiveness after exposure to CAPs in pulmonary hypertensive rats. Our findings also indicate that potential confounders need to be controlled in assessing airway responsiveness.

\section{REFERENCES}

Ackermann-Liebrich, U., Leuenberger, P., Schwartz, J., Schindler, C., Monn, C., and Bolognini, G. 1997. Lung function and long term exposure to air pollutants in Switzerland. Study on Air Pollution and Lung Diseases in Adults (SAPALDIA) Team. Am. J. Respir. Crit. Care Med. 155:122-129.

Cassee, F. R., Boere, A. J., Bos, J., Fokkens, P. H., Dormans, J. A., and van Loveren, H. 2002. Effects of diesel exhaust enriched concentrated PM2.5 in ozone preexposed or monocrotaline-treated rats. Inhal. Toxicol. 14:721-743.

Cheng, T. J., Hwang, J. S., Wang, P. Y., Tsai, C. F., Chen, C. Y., Lin, S. H., and Chan, C. C. 2003. Effects of concentrated ambient particles on heart rate and blood pressure in pulmonary hypertensive rats. Environ. Health Perspect. 111:147-150.

Clarke, R. W., Catalane, P. J., Koutrakis, P., Krishna, M,, Sioiutas, C., and Paulauskis, S. J. 1999. Urban air particulate inhalation alters pulmonary function and induces pulmonary inflammation in a rat model of chronic bronchitis. Inhal. Toxicol. 11:637656.

Clarke, R. W., Coull, B., Reinisch, U., Catalano, P., Killingsworth, C. R., Koutrakis, P., Kavouras, I., Murthy, G. G. K., Lawrence, J., Lovett, E., Wolfson, M., Verrier, R. L., and Godleski, J. J. 2000. Inhaled concentrated ambient particles are associated with hematologic and bronchoalveolar lavage changes in canines. Environ. Health Perspect. 108:1179-1187.

Dockery, D. W., and Pope, C. A. 1994. Acute respiratory effects of particulate air pollution. Annu. Rev. Public Health 15:107-132.

Godleski, J. J., Verrier, R. L., Koutrakis, P., Catalano, P., Coull, B., Reinisch, U., Lovett, E. G., Lawrence, J., Murthy, G. G., Wolfson, J. M., Clarke, R. W., Nearing, B. D., and Killingsworth, C. 2000. Mechanisms of morbidity and mortality from exposure to ambient air particles. Res. Rep. Health Effects Inst. 91:5-88, discussion 89103.

Goldsmith, C. A., Hamada, K., Ning, Y., Qin, G., Catalano, P., Krishna Murthy, G. G., Lawrence, J., and Kobzik, L. 1999. Effects of environmental aerosols on airway hyperresponsiveness in a murine model of asthma. Inhal. Toxicol. 11:981-998.

Goldsmith, C. A., Ning, Y., Qin, G., Imrich, A., Lawrence, J., Murthy, G. G., Catalano, P. J., and Kobzik, L. 2002. Combined air pollution particle and ozone exposure increases airway responsiveness in mice. Inhal. Toxicol. 14:325-347.

Gong, H., Linn, W. S., Sioutas, C., Terrell, S. L., Clark, K. W., Anderson, K. R., and Terrell, L. L. 2003. Controlled exposures of healthy and asthmatic volunteers to concentrated ambient fine particles in los angeles. Inhal. Toxicol. 15:305-325.

Gordon, T., Nadziejko, C., Schlesinger, R., and Chen, L. C. 1998. Pulmonary and cardiovascular effects of acute exposure to concentrated ambient particulate matter in rats. Toxicol. Lett. 96-97:285-288.

Hamada, K., Goldsmith, C. A., Goldman, A., and Kobzik, L. 2000. Resistance of very young mice to inhaled allergen sensitization is overcome by coexposure to an air-pollutant aerosol. Am. J. Respir. Crit. Care Med. 161:1285-1293.

Hamelmann, E., Schwarze, J., Takeda, K., Oshiba, A., Larsen, G. L., Irvin, C. G., and Gelfand, E. W. 1997. Noninvasive measurement of airway responsiveness in allergic mice using barometric plethysmography. Am. J. Respir. Crit. Care Med. 156:766-775.

Imich, A., Ning, Y., and Koblebizik, L. 2000. Insoluble components of concentrated air particles mediate alveolar macrophage response in vitro. Toxicol. Appl. Pharmacol. 167:140-150.

Kodavanti, U. P., Costa, D. L., and Bromnerg, P. A. 1998. Rodent models of cardiovascular disease: Their potential applicability in studies of air pollutant susceptibility. Environ. Health Perspect. 106:111130.

Lei, Y. C., Chan, C. C., Wang, P. Y., Lee, C. T., and Cheng, T. J. 2004. Effects of dust storm particles on inflammation markers in peripheral blood and bronchoalveolar lavage in pulmonary hypertensive rats. Environ. Res. 95:71-76.

Leikauf, G. D. 2002. Hazardous air pollutants and asthma. Environ. Health Perspect. 110(suppl. 4):505-526.

Lundblad, L. K. A., Irvin, C. G., Adler, A., and Bates, J. H. T. 2002. A reevaluation of the validity of unrestrained plethysmography. J. Appl. Physiol. 93:1198-1207.

Monn, C., and Becker, S. 1999. Cytotoxicity and induction of proinflammatory cytokines from human monocytes exposed to fine 
$\left(\mathrm{PM}_{2.5}\right)$ and coarse particles $\left(\mathrm{PM}_{10-2.5}\right)$ in outdoor and indoor air. Toxicol. Appl. Pharmacol. 155:245-252.

Ning, Y., Imrich, A., Goldsmith, C. A., Qin, G., and Kobzik, L. 2000. Alveolar macrophage cytokine production in response to air particles in vitro: Role of endotoxin. J. Toxicol. Environ. Health A 59:165-180.

Peacock, J. L., Symonds, P., Jackson, P., Bremner, S. A., Scarlett, J. F., Strachan, D. P., and Anderson, H. R. 2003. Acute effects of winter air pollution on respiratory function in schoolchildren in southern England. Occup. Environ. Med. 60:82-89.

Pekkanen, J., Timonen, K. L., and Ruuskanen, J. 1997. Effects of ultrafine and fine particles in urban air on peak expiratory flow among children with asthmatic symptoms. Environ. Res. 74:24-33.

Peters, A., Wichmann, H. E., Tuch, T., Heinrich, J., and Heyder, J. 1997. Respiratory effects are associated with the number of ultrafine particles. Am. J. Respir. Crit. Care Med. 155:1376-1383.

Pope, C. A. III, and Dockery, D. W. 1999. Epidemiology of particle effects. In Air pollution and health, Eds. S. T. Holgate, J. M. Samet, H. S. Koren, and R. L. Maynard, pp. 673-705. London: Academic Press.

Pope, C. A. III, Burnett, R. T., Thun, M. J., Calle, E. E., Krewski, D., and Ito, K. 2002. Lung cancer, cardiopulmonary mortality, and long-term exposure to fine particulate air pollution. J. Am. Med. Assoc. 287:1132-1141.
Salvi, S., Blomberg, A., Rudell, B., Kelly, F., Sandstrom, T., Holgate, S. T., and Frew, A. 1999. Acute inflammatory responses in the airways and peripheral blood after short-term exposure to diesel exhaust in healthy human volunteers. Am. J. Respir. Crit. Care Med. 159:702-709.

Schwartz, J. 1993. Particulate air pollution and chronic respiratory disease. Environ. Res. 62:7-13.

Schwartz, J., Slater, D., Larson, T. V., Pierson, W. E., and Koenig, J. Q. 1993. Particulate air pollution and hospital emergency room visits for asthma in Seattle. Am. Rev. Respir. Dis. 147:826831.

Schwartz, J., Dockery, D. W., Neas, L. M., Wypij, D., Ware, J. H., Spengler, J. D., Koutrakis, P., Speizer, F. E., and Ferris, B. G., Jr. 1994. Acute effects of summer air pollution on respiratory symptom reporting in children. Am. J. Respir. Crit. Care Med. 150:123401242.

Sioutas, C., Kim, S., and Chang, M. 1999. Development and evaluation of a prototype ultra-fine particle concentrator. J. Aerosol Med. 30:1001-1017.

Tunnicliffe, W. S., Harrison, R. M., Kelly, F. J., Dunster, C., and Ayres, J. G. 2003. The effect of sulphurous air pollutant exposures on symptoms, lung function, exhaled nitric oxide, and nasal epithelial lining fluid antioxidant concentrations in normal and asthmatic adults. $O c$ cup. Environ. Med. 60:e15. 
Copyright of Inhalation Toxicology is the property of Taylor \& Francis Ltd and its content may not be copied or emailed to multiple sites or posted to a listserv without the copyright holder's express written permission. However, users may print, download, or email articles for individual use. 
Copyright of Inhalation Toxicology is the property of Taylor \& Francis Ltd and its content may not be copied or emailed to multiple sites or posted to a listserv without the copyright holder's express written permission. However, users may print, download, or email articles for individual use. 